\title{
ENTRE O DIREITO, A POLÍTICA E A ECONOMIA: (RE)CONSTRUINDO A ANÁLISE INSTITUCIONAL COMPARATIVA*
}

\section{BETWEEN LAW, POLITICS AND ECONOMICS: (RE)CONSTRUCTING THE COMPARATIVE INSTITUTIONAL ANALYSIS}

\author{
Rafael de Oliveira Costa**
}

\begin{abstract}
RESUMO: o direito, a economia e a política, vislumbrados sob uma ótica eminentemente institucional, são as principais estruturas que compõem o sistema estatal. Este trabalho busca analisar, adotando como metodologia a análise institucional comparativa, o complexo emaranhado de processos de tomada de decisão, buscando definir a instituição mais apta a implementar uma determinada política pública, por meio de uma adaptação, para o cenário nacional, do modelo desenvolvido por Neil Komesar em Imperfect alternatives: choosing institutions in law, economics and public policy.
\end{abstract}

PALAVRAS-CHAVE: Análise institucional comparativa. Políticas públicas. Processos de tomada de decisão.

ABSTRACT: Law, economics, and politics, seen in a primarily institutional perspective, are the main structures that make up the state system. This paper seeks to analyze, by adopting comparative institutional analysis, the complex tissue of decision-making processes, aiming to define the most suitable institution to implement a determined public policy, through an adaptation, for the national scene, of the model developed by Neil Komesar in Imperfect alternatives: choosing institutions in law, economics and public policy.

KEYWORDS: Comparative institutional analysis. Decision-making processes. Public policies.

\footnotetext{
* O presente estudo é fruto de pesquisa desenvolvida junto à Universidade de Wisconsin (EUA). Diante das dimensões deste ensaio, torna-se impossível abordar em sua totalidade a metodologia desenvolvida por Neil Komesar. Espero, contudo, que estas breves considerações sejam capazes de trazer a lume discussões até agora ignoradas pela doutrina nacional e que podem, sem sombra de dúvidas, colaborar para a adequada implementação de políticas públicas no Brasil.

** Graduado em Direito pela Universidade Federal de Minas Gerais (UFMG) / Universidade de Wisconsin (EUA). Mestre e Doutor em Direito pela Universidade Federal de Minas Gerais (UFMG). Promotor de Justiça no Estado de São Paulo.
} 


\section{INTRODUÇÃO}

A ciência, a ciência, a ciência...

Ah, como tudo é nulo e vão!

A pobreza da inteligência

Ante a riqueza da emoção!

Aquela mulher que trabalha

Como uma santa em sacrifício,

Com quanto esforço dado ralha!

Contra o pensar, que é o meu vício!

A ciência! Como é pobre e nada!

Rico é o que alma dá e tem.

(PESSOA, 1981, p. 455)

Frankenstein, obra literária das mais influentes, relata as mudanças que a criatura provoca em seu criador, o cientista. Igualmente, as criaturas imaginadas pelos juristas incluindo não apenas o direito, mas também a economia e a política - modificam as concepções de seus criadores. Assim, a análise institucional comparativa, desenvolvida pelo professor de direito constitucional da Universidade de Wisconsin (EUA) e do Instituto Universitário Europeu (EUI), Neil Komesar (1994), vem modificando a análise dos processos de tomada de decisão, sua própria estrutura e seus criadores. Como a minha referência a Frankenstein sugere, a análise institucional comparativa propõe, à implementação de políticas públicas, novos riscos e desafios para problemas ainda não solucionados.

Hodiernamente, a complicada teia de relações que se estabelece entre as instituições implica na dificuldade em compreendê-las, especialmente em razão da complexidade dos processos de tomada de decisão (decision-making process) de que participam. A economia, a política e o direito assumem papel primordial, uma vez que são responsáveis pelos mais importantes processos de tomada de decisão, determinando a própria estrutura da sociedade contemporânea.

A new institutional economics, nova vertente institucionalista da análise econômica, procura estudar o papel das instituições e as suas influências no ambiente normativo, deitando suas raízes em artigo publicado por Ronald Coase (1960).

No estudo, Coase sustenta que, sem os custos de transação, a distribuição dos direitos de propriedade pode internalizar conflitos e externalidades. Em outras palavras, quando pessoas afetadas por externalidades podem negociar sem custos de transação, são capazes de chegar a um acordo no qual as externalidades acabam sendo internalizadas (COASE, 1960). 
Nesse liame, a new institutional economics se torna indispensável para que se possa compreender a internalização das externalidades e o design institucional existente na sociedade.

Hodiernamente, contudo, a metodologia abrange um conjunto complexo de princípios e critérios, incluindo questões relacionadas à eficiência e à distribuição de riquezas. Entre os muitos aspectos submetidos à análise, encontram-se os arranjos organizacionais, os direitos reais, os custos de transação, os modos de governança, as normas sociais, o capital social, o comportamento estratégico, o oportunismo, o risco moral, o poder de negociação, entre outros.

Dentre os principais doutrinadores associados à temática, pode-se mencionar Harold Demsetz, Steven Cheung, Avner Greif, Yoram Barzel e quatro ganhadores de prêmio Nobel: Ronald Coase, Douglass North, Elinor Ostrom e Oliver Williamson.

Nas últimas décadas, Neil Komesar passou a desenvolver uma metodologia que pretende abarcar as relações entre o direito, a economia e a política.

Komesar é, sem sombra de dúvidas, um dos principais expoentes do direito americano do último meio século. Graduado em direito pela Universidade de Chicago e com doutorado em economia pela mesma instituição, os trabalhos por ele publicados servem de base para inúmeros estudos, que vão desde o direito ambiental e os direitos reais, até a resolução internacional de disputas e os direitos humanos. Suas principais contribuições, contudo, encontram-se na reformulação da análise de políticas públicas, especialmente na racionalização dos processos de tomada de decisão.

Komesar tem dois objetivos principais. Em primeiro lugar, atentar para o fato de que qualquer reforma legislativa não atingirá seu desiderato se não for submetida à análise institucional comparativa, ou seja, sem uma comparação cuidadosa das características do processo político, da economia e do processo judicial, capazes de tornar uma dessas instituições mais apta que as demais em um dado contexto. Em segundo lugar, Komesar pretende ensinar como deve ser aplicada a análise institucional comparativa, ao identificar as características das instituições alternativas que podem torná-las mais aptas ao alcance de determinadas políticas públicas. Por este motivo, todas as áreas do direito foram - e continuam sendo - moldadas pelas contribuições de Komesar. No que concerne às relações entre o direito, a política e a economia, vale ressaltar duas obras principais: Imperfect alternatives e Law's limits.

Na primeira delas, Komesar (1994) apresenta uma metodologia para a análise da seleção institucional. Trata-se de uma nova perspectiva universalizante que atenta para o 
comportamento dos processos de tomada de decisão nas searas do direito, da política e da economia.

Em Law's limits, o professor da Universidade de Wisconsin aprofunda dois aspectos do método construído na obra anterior: o modelo das duas forças e a complexidade interinstitucional (KOMESAR, 2002).

Contudo, para compreender a metodologia desenvolvida por Komesar, é preciso assumir que o foco da análise institucional comparativa é a alocação da autoridade no decision-making process, buscando não só determinar a instituição mais apta para implementar uma determinada política pública ("decide who decides") ${ }^{1}$, mas também solucionar demandas que envolvam o Direito e a concretização de políticas públicas (KOMESAR, 1994, p. 9-13).

Assim, a "seleção institucional" nada mais é do que "a decisão de quem decide", ou seja, o resultado final do processo de tomada de decisão, estabelecendo a instituição mais apta a implementar uma dada política pública (Ibid., p. 3). O termo “institucional”, segundo Komesar, reflete o fato de que a decisão de quem decide é realmente uma decisão do que se decide. Vejamos:

O termo "institucional" reflete a realidade de que a decisão de quem decide é realmente uma decisão do que se decide. Os responsáveis pelos processos de tomada de decisão não são indivíduos ou um pequeno número de indivíduos. São processos complexos, como o processo político, a economia e o processo judicial, nos quais a interação de vários participantes molda o desempenho. (Ibid., p. 16) ${ }^{2}$

Assim, ao contrário do que normalmente pensam aqueles que analisam o comportamento das instituições, as diversas alternativas nos processos de tomada de decisão não são individuais ou relacionadas a grupos de pessoas (Ibid., loc. cit.). Ao contrário, trata-se de processos complexos, tais como a política - por meio do processo legislativo -, a economia - por meio do processo de circulação de riquezas - e o direito - por meio do processo judicial -, nos quais a "performance de cada instituição" é dada pela interação entre

\footnotetext{
${ }^{1}$ São diversas as aplicações desta análise. Dentre elas, encontra-se não só a consolidação de uma constituição - o processo de constitution building -, mas também uma ampla variedade de decisões tomadas não apenas pelo judiciário, mas pela economia e pelo legislativo.

${ }^{2}$ No original: "The term 'institutional' reflects the reality that the decision of who decides is really a decision of what decides. The alternative decision-makers are not individuals or even small numbers of individuals. They are complex processes, such as the political process, the market process, and the adjudicative process, in which the interaction of many participants shape the performance."
} 
seus participantes - e não, como acreditam inúmeros juristas, a partir de um a priori (Ibid., p. 16-18).

Para Komesar, a "seleção de instituições" não se resume a uma análise institucional simples. Ao contrário, trata-se de uma análise institucional comparativa, que pretende examinar as escolhas possíveis entre as diversas alternativas de decision-making processes, culminando na determinação da instituição mais apta à implementação da política pública em apreço (Ibid., p. 3-21).

Mas, como é possível essa análise? É o que procuraremos responder no tópico seguinte.

\section{DO PAPEL DA ECONOMIA E DA FILOSOFIA NO DIREITO}

A seleção institucional que normalmente é realizada se baseia na análise institucional simples, ou seja, na análise de uma só instituição.

A metodologia-padrão utilizada para enfocar o direito e a economia é normalmente baseada na variação da habilidade de uma só instituição: o mercado. Nesse liame, a análise econômica do direito representa corrente do pensamento legal que incorpora métodos e ideias da economia na análise de casos submetidos ao crivo do poder judiciário, predizendo os efeitos do ordenamento jurídico (POSNER, 2002).

Além disso, a vertente normativa da análise econômica do direito tem como intuito tecer recomendações de política jurídica, baseando-se nas consequências econômicas das diferentes posições que podem ser adotadas pelo julgador. O conceito-chave para os defensores desta corrente é a eficiência - neste caso, a eficiência de Kaldor-Hicks.

Contudo, a análise institucional comparativa pretende ir mais longe, abarcando, a um só tempo, a complexidade das principais instituições existentes, em especial o direito, a economia e a política. Por este motivo, a concretização da seleção institucional é complexa. A escolha é, sempre, "uma escolha entre alternativas imperfeitas" (KOMESAR, 1994, p. 5). As potencialidades e fraquezas de uma instituição, quando comparadas às demais, variam segundo as circunstâncias do caso concreto (Ibid.). Assim, se em alguns casos o poder judiciário se apresenta como a melhor instituição para a tutela de determinados direitos, em outros, a tarefa poderá ser mais bem realizada pelo processo legislativo ou pelo mercado (Ibid.).

Ressalte-se, por oportuno, que a metodologia utilizada por Komesar não é a única capaz de realizar a análise institucional comparativa. 
Assim, em The legal process: basic problems in the making and application of law, Henry Hart e Albert Sacks (1994) apresentam uma teoria do processo legal baseada nas relações entre os três principais ramos do governo - executivo, legislativo e judiciário. A teoria permite a análise de políticas públicas sob uma vasta gama de perspectivas - incluindo o direito constitucional, administrativo e processual. No entanto, a ótica empregada é significativamente diferente daquela proposta por Komesar: trata-se de uma imagem idealizada das instituições, como se funcionassem em conjunto e de modo racional.

A análise proposta por Komesar, de outra forma, abarca não apenas a racionalidade e os benefícios das instituições, mas também as suas falibilidades e dificuldades, tornando-a mais complexa e realista.

De outra forma, Robert Dahl e Charles Lindblom (1953), em Politics, economics and welfare, examinam diferentes aspectos do fenômeno sociológico, incluindo o sistema de preços, a hierarquia e o complexo conceito de poliarquia. A teoria de Dahl e Lindblom tem escopo mais amplo do que aquele proposto por Komesar, uma vez que abarca a questão da atividade política e econômica em nível global.

De qualquer modo, é importante deixar claro que, no campo da análise institucional comparativa, não basta identificar as relações entre o direito, a economia e a política.

Por este motivo, a potencialidade da análise institucional comparativa e a limitação da análise institucional simples podem ambas ser percebidas na análise econômica realizada por Richard Posner ${ }^{3}$. Isso porque o próprio conceito de análise institucional simples atenta para a necessidade de ir mais longe, construindo um modelo (framework) mais complexo, que permita a análise simultânea das diversas instituições existentes, sem se prender a qualquer delas (KOMESAR, 1994).

Nesse sentido, Komesar sustenta que a questão não é "quando a economia funciona melhor que o legislativo" ou "quando o processo judicial atua melhor que a economia", mas, dado um conjunto de circunstâncias, qual das instituições é a mais indicada para implementar determinada política pública, especialmente diante dos novos contornos que vem tomando o processo coletivo (Ibid., p. 9-12).

Contudo, a aplicação da análise institucional comparativa é difícil. As instituições são abrangentes e complexas, e a tarefa de delimitar suas fronteiras é árdua (Ibid.). Mais

\footnotetext{
${ }^{3}$ Posner emprega a análise institucional simples para fornecer uma visão aprofundada de uma vasta gama de questões legais centradas na habilidade de uma instituição central. Contudo, por realizar a análise a partir de instituição não judicial - a economia -, Posner falha na realização da análise institucional. Segundo Komesar (1994), é preciso ir além e perceber a versatilidade analítica que oferece ao pesquisador do direito a utilização da análise institucional comparativa.
} 
importante, a comparação das instituições requer a identificação de pontos de contato entre elas, o que demanda a construção de um modelo capaz de identificar e comparar as capacidades do direito, da economia e da política (Ibid.).

A proposta de Komesar para solucionar este aparente impasse encontra-se na participation-centered approach - metodologia centrada na participação (Ibid.). Segundo o jusfilósofo, a única forma de concretizar a seleção institucional e, deste modo, realizar uma verdadeira análise institucional comparativa, é utilizar um elemento compartilhado por todas as instituições: a participação de seus atores (Ibid.).

Em outras palavras, a variação no desempenho de uma dada instituição encontra-se intimamente vinculada à participação dos atores comuns a todas as instituições consumidores, produtores, eleitores, lobistas e litigantes (Ibid.). A fusão de todos esses atores, os quais atuam conjuntamente sobre um background institucional de complexas relações institucionais, permite a realização da verdadeira análise institucional comparativa (Ibid.). Em suma, a metodologia centrada na participação permite identificar as ações dos participantes como o critério de avaliação do funcionamento dessas mesmas instituições (Ibid.).

Assim, o modelo básico de participação institucional tem como fundamento um simples modelo matemático: o grau de participação é determinado pela interação entre os benefícios e os custos da participação (Ibid.).

Os benefícios enfocam a distribuição de interesses entre os indivíduos envolvidos. Os aspectos centrais a serem examinados são a média de interesses per capita e a extensão na qual os interesses per capita variam entre os envolvidos (Ibid.).

No que concerne aos custos de participação - custos de transações, custos de litígios ou custos de participação no processo político -, temos duas grandes categorias: os custos de organização e os custos de informação (Ibid.).

Os custos de organização dizem respeito aos interesses per capita na mobilização de um grupo para a defesa de uma dada política pública.

De outro modo, os custos de informação estão presentes em praticamente qualquer análise: a organização é em si mesma dependente da informação e, sem ela, não é capaz, sequer, de tomar ciência das medidas necessárias para a implementação de uma dada política pública.

A fim de que seja possível uma apreciação mais profunda da gama de objetivos não vinculados ao conceito de eficiência e das dificuldades em integrá-los, o modelo desenvolvido por Komesar faz uso da teoria de justiça de John Rawls (1971). 
A utilidade da teoria rawlsiana, nesse contexto, está vinculada à sua versatilidade e abrangência, tornando-a capaz de captar as hipóteses nas quais a eficiência não é o elemento fundamental para a análise, mas, sim, a discussão sobre o direito e seu desenvolvimento como um todo e, em especial, a sua concepção de proteção aos direitos fundamentais (KOMESAR, 1994).

Ora, assim como ocorre com a alocação eficiente de recursos, a aceitabilidade de objetivos sociais não nos diz virtualmente nada sobre o que o direito é ou deveria ser. Em outras palavras, a tutela de direitos fundamentais por meio de um sistema avançado de garantias em nada influencia a seleção institucional. Portanto, a teoria de Rawls - exatamente porque se aproxima de uma teoria pura das políticas públicas, desenhando contornos institucionais e evitando qualquer anúncio específico sobre a natureza do direito - se apresenta como a melhor opção para a análise proposta por Komesar (Ibid.).

Assim, a eterna busca por uma teoria que descreva com perfeição as imprecisões da realidade é o objetivo de todo cientista. Komesar, por sua vez, pretende desenvolver um modelo para análise institucional que garanta maior "qualidade" às decisões relacionadas à implementação de políticas públicas. As ferramentas da análise institucional comparativa são desenvolvidas para serem usadas em diferentes contextos legais, fornecendo meios para avaliação de políticas públicas que transcendam simples debates sobre valores e objetivos sociais (Ibid., p. 20-38).

Devido à conturbada configuração institucional brasileira e suas inúmeras modificações em tempos recentes, o país se apresenta como uma área fértil para o uso da análise institucional comparativa. Ao ignorarmos a seleção institucional, podemos implementar políticas públicas inferiores (Ibid.), uma vez que as diferentes instituições possuem distintas habilidades para implementar políticas públicas: quando uma instituição menos apta decide, os resultados podem ser desastrosos (Ibid.). O objetivo de Komesar é desenvolver uma nova metodologia, por meio da análise institucional comparativa, que modifique este panorama. E que, mais uma vez, as criaturas, criadas por nós, juristas, modifiquem seus criadores (Ibid.).

\section{FUNDAMENTOS DA ANÁLISE INSTITUCIONAL COMPARATIVA}

Como deixamos claro no tópico anterior, a participação institucional depende, principalmente, dos custos e benefícios da participação. 
O modelo, contudo, apresenta três aspectos principais. Em primeiro lugar, ele se baseia em escolhas racionais. ${ }^{4}$ Isso porque, a partir de escolhas racionais, o analista não poderá presumir “a perfeição de um mundo imperfeito" (Ibid., p. 27); ou seja, não é possível assumir a existência de informações ou transações a custo zero. Tais assunções, segundo o Teorema de Coase ${ }^{5}$, conduziriam a um erro na análise. No entanto, fundamentar o modelo em um sistema de escolhas racionais significa que toda uma gama de cálculos de benefícios e custos - inclusive os custos da realização dos próprios cálculos - deve ser levada em consideração (Ibid.).

Em segundo lugar, o modelo concebe os processos de tomada de decisão como massivos, complexos e dependentes das interações entre um grande número de participantes (Ibid.). Os resultados, no campo econômico, decorrem das interações entre a massa de consumidores e os fornecedores. A influência dos votantes, lobistas e outros grupos caracteriza o funcionamento do processo político. Até mesmo o poder judiciário pode ser concebido como um processo - um processo de prestação jurisdicional -, no qual a dinâmica do litígio determina a forma como os juízes decidem (Ibid.).

Em terceiro lugar, nenhuma seleção institucional pode ignorar a escassez e os custos. O processo judicial, em particular, é significativamente pequeno e frágil quando comparado às demais alternativas - o mercado e processo político (Ibid.). Suas características e elementos estruturais refletem a impossibilidade de sua expansão na mesma proporção e velocidade com que as demais instituições se expandem (Ibid.). E a tendência é o crescimento da população e da complexidade, levando à deterioração da habilidade das instituições (Ibid.). Tudo isso leva à necessidade de uma séria análise comportamental das instituições na implementação de políticas públicas (Ibid.).

\section{PRESSUPOSTOS METODOLÓGICOS}

O método centrado na participação busca solucionar o problema da seleção institucional por meio de uma ferramenta simples, que parte das seguintes premissas:

\footnotetext{
${ }^{4}$ Como Posner (2002, p. 3) bem pondera em seu Economic analysis of law, "o domínio da economia é muito mais amplo. Tal como concebido neste livro, a economia é a ciência da escolha racional em um mundo - o nosso mundo - no qual os recursos são limitados em relação às necessidades humanas."

5 "Em um mundo em que há custos de redistribuição dos direitos estabelecidos pelo sistema legal, os tribunais, em casos relacionados com o direito de vizinhança, estão, em verdade, tomando uma decisão sobre o problema econômico e determinando como os recursos devem ser empregados. As cortes estão conscientes disso e costumam fazer, embora nem sempre de uma forma muito explícita, uma comparação entre as vantagens e as desvantagens, impedindo decisões com efeitos nocivos." (COASE, 1960, p. 27)

Revista da Faculdade de Direito - UFPR, Curitiba, vol. 59, n. 2, p. 75-90, 2014.
} 
1. A seleção de objetivos sociais ou valores é insuficiente para uma análise do direito, seja ela descritiva ou prescritiva. Por este motivo, a seleção institucional é fundamental para o entendimento/adaptação do direito (KOMESAR, 1994).

2. A análise institucional deve ser comparativa. A análise institucional simples não é suficiente, não importa quão complexa ou sofisticada, uma vez que não é capaz de avaliar os benefícios/deficiências das demais instituições (Ibid.).

a. As instituições, em geral, tendem "a se mover juntas". Assim, quando uma delas apresenta seu melhor desempenho, as outras também apresentam. De outro modo, quando uma delas tem o seu desempenho deteriorado, as outras também sofrem a mesma deterioração (Ibid., p. 23).

b. Existem hipóteses nas quais uma determinada instituição apresenta vantagens significativas em relação às demais (Ibid.).

3. A análise institucional deve ser centrada na participação. Como processos de tomada de decisões, as instituições compreendem uma complexa gama de interações. Consequentemente, para que seja possível avaliar essas instituições é necessário que se atente para as ações de seus diversos participantes. O grau de envolvimento dos diferentes participantes, contudo, é afetado por inúmeros aspectos, dentre eles:

a. A motivação individual dos participantes pouco influencia o comportamento institucional (Ibid.).

b. Os custos de informação desempenham um papel essencial na determinação da participação institucional e, portanto, na performance da instituição. Em outras palavras, tanto as atividades majoritárias, como os litígios judiciais e a atuação do mercado, são afetados pelos custos de informação (Ibid.).

c. Em relação ao processo político, a metodologia centrada na participação é fortalecida quando emprega, no cenário brasileiro, o modelo das múltiplas forças. O modelo das múltiplas forças, ao considerar a possibilidade de atuações majoritárias e minoritárias em uma estrutura formada por diversos grupos - com diferentes interesses - reflete a participação política de forma mais abrangente do que a perspectiva oferecida pela teoria dos grupos de interesses da política - adotada por Komesar (1994) - e que estabelece as suas bases sobre a atuação de apenas uma força.

d. Em relação à economia, a perspectiva centrada nos custos das transações fundada na teoria de Ronald Coase - permite a análise centrada na participação, uma vez que atenta para o papel desempenhado pelos "benefícios transacionais” (Ibid., p. 23). 
e. Em relação ao processo judicial, a metodologia centrada na participação fornece uma gama maior de detalhes do que os métodos tradicionais - que enfocam apenas a independência judicial. Isso porque a metodologia centrada na participação permite considerar, a um só tempo, os custos de participação associados com a independência judicial, as severas restrições de recursos e a competência constitucionalmente fixada para a atuação de juízes e tribunais, produzindo resultados mais fidedignos com o desempenho da prestação jurisdicional (Ibid.).

Fixadas essas premissas, fica fácil concluir que a vasta abrangência da análise institucional comparativa (ao incluir virtualmente qualquer decision-making process, até mesmo as hipóteses mais abrangentes de constitution-building) reflete a sua importância na implementação de políticas públicas.

A teoria de Komesar busca libertar juristas, cientistas políticos e economistas das amarras da alocação eficiente de recursos e das restrições impostas pelas motivações pessoais, passando a conceber o direito, a economia e a política como sistemas que, apesar de sujeitos a inúmeras falhas, buscam estabelecer uma lógica para suas ações (Ibid.).

Assim, os modelos centrados na análise institucional simples (focados no plano econômico ou político) e os modelos de natureza não econômica (que enfocam tão somente a seleção de objetivos) ignoram a complexidade e importância da seleção institucional, como ferramenta essencial para a compreensão do fenômeno jurídico (Ibid.).

Em última instância, o objetivo do modelo desenvolvido por Komesar é a reforma da própria sociedade, na medida em que a análise do fenômeno jurídico não deve focar, apenas e tão somente, a seleção de “objetivos sociais" ou "políticas de cunho jurídico” (Ibid., p. 54).

Em suma, limitar o modelo à análise de determinados objetivos sociais é privá-lo de sua maior vantagem, qual seja, a versatilidade que possui para analisar o comportamento institucional. Em outras palavras, Komesar não almeja apenas a seleção de objetivos sociais, mas a formação de uma estrutura analítica que possibilite garantir segurança e "qualidade" às decisões institucionais - e, consequentemente, às jurídicas (Ibid., p. 52).

\section{APLICAÇÃO}

Para aplicar a análise institucional de modo funcional, a metodologia proposta por Komesar inova não apenas pela forma como realiza a análise, mas também introduz uma nova concepção da relação entre instituições, imersa em dois novos parâmetros analíticos - a filosofia e a segurança jurídica. 
Conforme ressaltamos anteriormente, a análise institucional comparativa se baseia na mensuração da participação dos diferentes atores. O fundamento da metodologia centrada na participação está na premissa de que não acontecerão mudanças no cenário jurídico como um todo sem que as partes interessadas busquem a sua realização (Ibid.).

A seleção institucional, por sua vez, pretende representar o mundo empírico, especialmente quando as instituições não têm legitimidade ou governabilidade - como é o caso brasileiro. Em verdade, as instituições tendem a se mover juntas: quando uma delas está no seu "melhor", ou seja, tem um bom desempenho para a solução das demandas que lhe são postas, as demais também estão (Ibid., p. 9-54).

Dessa forma, Komesar visa identificar qual das instituições apresenta o melhor desempenho para a implementação de uma determinada política pública. O problema, no entanto, é que esta seleção se dá sempre entre alternativas imperfeitas - o processo jurisdicional, o processo legislativo e o mercado - e a aplicação dessas instituições varia segundo suas habilidades para solucionarem as demandas (Ibid.).

Para tanto, o modelo é capaz de capturar a variação do desempenho de cada instituição segundo a participação de atores comuns a todas elas - sejam eles consumidores, fornecedores, eleitores, litigantes etc.

Em suma, a universalidade das instituições é analisada a partir de uma única variável: a participação. Isso porque, segundo Komesar (1994), a identificação das ações de uma massa de participantes é o fator que melhor reflete os diferentes modos de atuar das diferentes instituições, uma vez que elas são extremamente afetadas pelo comportamento das ações em massa. A participação, portanto, é o melhor parâmetro para a análise institucional porque, uma vez que se encontra presente em todas as instituições, serve como parâmetro para comparação entre todas elas (Ibid.).

Portanto, algumas características dos custos e benefícios da participação são comuns a todas as instituições. Em geral, quanto mais difuso um dado interesse, menor será o interesse de cada pessoa no resultado e maiores serão as chances de que um pequeno acréscimo nos custos da participação efetue uma mudança na promoção de determinado interesse (Ibid.). 
Ao mesmo tempo, os custos de organização serão maiores para interesses difusos, porque será mais difícil identificar aqueles que compartilham interesses e prevenir "free riders" ${ }^{\prime 6}$ (Ibid., p. 9-54).

Além disso, os custos de participação também aumentam quando o interesse é complexo ou altamente técnico, porque interesses desse tipo demandam tempo e energia para a compreensão da própria informação (Ibid.).

Em suma, os custos de participação dependem não apenas dos custos de aquisição de informações sobre as políticas públicas existentes e dos meios para realização da mudança, mas também dos custos de organização - efetiva mobilização do grupo interessado em promover a mudança (Ibid.).

Mas como aplicar o modelo?

Segundo Komesar, o analista deve, em primeiro lugar, selecionar a política pública que deseja promover.

Em seguida, deve-se avaliar a habilidade relativa de cada instituição, segundo o grau de participação provável de cada grupo. Nessa fase, deve-se considerar como os custos de participação e de organização inerentes a cada instituição se comportam frente aos benefícios esperados na utilização dessa mesma instituição. Em outras palavras, sob a égide da metodologia centrada na participação, o desejo coletivo dos atores de participarem de uma determinada instituição determina a competência da instituição (Ibid.).

Por fim, deve-se analisar se a decisão institucional está contida nos limites traçados pelo ordenamento jurídico para cada instituição. ${ }^{7}$

Em síntese, no primeiro estágio seleciona-se a política pública a ser implementada; no segundo, elege-se a instituição mais apropriada para promovê-la; e, no terceiro, realiza-se uma análise da constitucionalidade das medidas necessárias à concretização.

Conclui-se, pois, que a metodologia centrada na participação envolve uma análise positiva: a identificação dos diferentes grupos interessados em uma política pública e os custos/benefícios a cada grupo em quaisquer das três instituições. O produto dessa análise é a seleção da melhor instituição para resolver a questão, dentro dos limites traçados pelo ordenamento jurídico.

\footnotetext{
6 Free riders, no sentido aqui utilizado, são todos aqueles que não agem objetivando um resultado verdadeiramente positivo. Em verdade, eles apenas se aproveitam de situações vantajosas para obterem as medidas que desejam das diferentes instituições (KOMESAR, 1994, p. 77).

${ }^{7}$ Embora Komesar não aborde expressamente este terceiro estágio, entendemos tratar-se de etapa fundamental para o modelo, na medida em que é impossível vislumbrar a seleção institucional sem a filtragem da sua compatibilidade com o próprio ordenamento jurídico.
} 


\section{DIREITO CONSTITUCIONAL E ANÁLISE INSTITUCIONAL COMPARATIVA}

Como anteriormente ressaltado, os valores e princípios constitucionais são importantes diretrizes para o intérprete. Contudo, sozinhos eles não nos dizem nada sobre as políticas públicas e processos de tomada de decisão.

No campo constitucional, a vasta abertura interpretativa nada mais é do que uma abertura para a seleção institucional: o intérprete, para fixar o sentido da norma, deve conferir a determinada instituição a competência para solucionar litígios de diferentes espécies.

Por este motivo, as seleções realizadas pelo poder constituinte (constitution-making) envolvem a estrutura das instituições a serem criadas e a alocação de autoridade nos processos de tomada de decisão. Assim, para decidir se um princípio ou regra deve incidir em um caso concreto é necessário construir um modelo analítico complexo que explique essa relação. E esse modelo é, em verdade, a própria seleção institucional (KOMESAR, 1994). A seleção institucional é uma translação necessária para garantir efetividade a qualquer princípio ou regra (Ibid.).

Assim, o processo político, por exemplo, interpreta a constituição quando adota políticas públicas que procuram promover a igualdade social. E o faz independentemente de qualquer referência à carta magna como fundamento para se chegar à solução (Ibid.).

Ao mesmo tempo, as decisões prolatadas pelo poder judiciário se baseiam na constituição, uma vez que, se toda interpretação feita por este poder é sempre uma interpretação (ainda que indiretamente) da carta magna, não se pode ignorá-la ao decidir (Ibid.).

Contudo, o tamanho institucional do processo judicial e do processo político possui uma diferença gigantesca, visto que o primeiro é significativamente menor e de difícil expansão quando comparado com o segundo. Por este motivo, é impossível o controle de constitucionalidade de toda interpretação constitucional realizada pelo processo político, mesmo diante da ocorrência de erros grosseiros.

$\mathrm{Na}$ atualidade, grande parte dos diplomas normativos que regem a economia e as temáticas sociais encontra-se eivado de erros decorrentes do mau-funcionamento do processo político (Ibid.). Assim, o fato de a revisão judicial envolver apenas uma pequena parcela da interpretação constitucional realizada pelo processo político não é explicado pela ausência de erros grosseiros. A única explicação plausível para este problema está na falta de recursos e nos severos limites institucionais do poder judiciário (Ibid.). 
Nos últimos anos, no entanto, as instituições têm se tornado cada vez maiores e mais complexas. E a crescente discrepância de tamanho entre os processos judicial e político é suficiente para ditar o futuro do controle de constitucionalidade e de todo o direito constitucional (Ibid.).

A análise institucional simples dispensa pouca atenção ao direito constitucional devido à sua preocupação com os atributos do mercado. Nos casos que envolvem o direito constitucional, os tribunais resolvem controvérsias que abrangem a estrutura básica do Estado e do governo, a atuação legislativa e os papéis desempenhados por várias instituições públicas. Assim, a análise institucional simples, que tem como foco o mercado, acaba por desconsiderar o direito constitucional. Trata-se de análise incompleta que, ao fornecer alguns parâmetros válidos, exclui um aspecto crucial: as imperfeições das instituições.

Por este motivo, as decisões tomadas no âmbito do direito constitucional devem ser vislumbradas sob a égide da análise institucional comparativa. Uma constituição, seja ela dogmática ou costumeira, aloca competências. Em nosso sistema, com uma tradição separatista entre as competências federais, estaduais e municipais, a variedade de alternativas institucionais torna-se ainda mais ampla.

Em suma, devido ao fato de cada uma dessas instituições possuir as suas próprias imperfeições e potencialidades, a seleção constitucional é sempre complexa e árdua, e não pode ser evitada por aquele que pretenda implementar políticas públicas com qualidade.

\section{CONCLUSÃO}

A seleção institucional e a análise institucional comparativa podem melhorar drasticamente a implementação de políticas públicas.

No Brasil, evidentemente, a sua aplicação é ainda incipiente, para não dizer nula.

Contudo, para que as reformas de grande amplitude no sistema jurídico sejam bem sucedidas, é necessária uma análise baseada na seleção institucional. Mas não é possível esconder as dificuldades imanentes a este tipo de análise. Por este motivo, a não ser que passemos a utilizar ferramentas poderosas de seleção institucional, as reformas que vêm sendo implantadas (no Código de Processo Civil, no Código de Processo Penal, na Execução Penal, no Código Penal, no Código Eleitoral, entre outras) não passarão de propostas ilusórias, incapazes de efetivamente promover o aprimoramento do ordenamento jurídico.

Em suma, a comunidade jurídica possui um considerável conhecimento acumulado acerca das instituições e da implementação de políticas públicas, mas precisa desejar correr os 
riscos associados à exploração de novos horizontes. Não é certo quão longe os investimentos nesses riscos nos levarão. Mas é certo que não iremos a lugar algum se os evitarmos.

\title{
REFERÊNCIAS
}

COASE, Ronald H. The problem of social cost. In: The Journal of Law and Economics, v. III, Chicago: University of Chicago Press, 1960.

DAHL, Robert A.; LINDBLOM, Charles E. Politics, economics and welfare. New York: Harper \& Brothers, 1953.

HART, Henry M.; SACKS, Albert M. The legal process: basic problems in the making and application of law. Westbury: Foundation Press, 1994.

KOMESAR, Neil K. Imperfect alternatives: choosing institutions in law, economics and public policy. Chicago University Press: Chicago, 1994.

Law's limits. Cambridge: Cambridge University Press, 2002.

NORTH, Douglass C. Institutions, institutional change and economic performance. Cambridge: Cambridge University Press, 1990.

PESSOA, F. Obra poética. Rio de Janeiro: Aguilar, 1981.

POSNER, Richard A. Economic analysis of law. 6. ed. Chicago: Aspen, 2002.

RAWLS, John. A theory of justice. Massachusetts: Harvard University Press, 1971.

\section{BETWEEN LAW, POLITICS AND ECONOMICS: (RE)CONSTRUCTING THE COMPARATIVE INSTITUTIONAL ANALYSIS}

\begin{abstract}
Law, economics, and politics, seen in a primarily institutional perspective, are the main structures that make up the state system. This paper seeks to analyze, by adopting comparative institutional analysis, the complex tissue of decision-making processes, aiming to define the most suitable institution to implement a determined public policy, through an adaptation for the national scene of the model developed by Neil Komesar in Imperfect alternatives: choosing institutions in law, economics and public policy.
\end{abstract}

KEYWORDS: Comparative institutional analysis. Decision-making processes. Public policies. 